\title{
Effect of posture on oxygenation and respiratory muscle strength in convalescent infants
}

\author{
G Dimitriou, A Greenough, L Pink, A McGhee, A Hickey, G F Rafferty
}

Arch Dis Child Fetal Neonatal Ed 2002;86:F147-F150

See end of article for authors' affiliations

\section{Correspondence to:}

Professor Greenough

Department of Child

Health, King's College

Hospital, London SE5 9RS,

UK;

anne.greenough@kcl.ac.uk

Accepted

13 November 2001
Objective: To determine if differences in respiratory muscle strength could explain any posture related effects on oxygenation in convalescent neonates.

Methods: Infants were examined in three postures: supine, supine with head up tilt of $45^{\circ}$, and prone. A subsequent study was performed to determine the influence of head position in the supine posture. In each posture/head position, oxygen saturation $\left(\mathrm{SaO}_{2}\right)$ was determined and respiratory muscle strength assessed by measurement of the maximum inspiratory pressure (PIMAX).

Patients: Twenty infants, median gestational age 34.5 weeks (range 25-43), and 10 infants, median gestational age 33 weeks (range 30-36), were entered into the first and second study respectively.

Results: Oxygenation was higher in the prone and supine with $45^{\circ}$ head up tilt postures than in the supine posture $(p<0.001)$, whereas PIMAX was higher in the supine and supine with head up tilt of $45^{\circ}$ postures than in the prone posture $(p<0.001)$. Head position did not influence the effect of posture on PIMAX or oxygenation.

Conclusion: Superior oxygenation in the prone posture in convalescent infants was not explained by greater respiratory muscle strength, as this was superior in the supine posture. p

n the perinatal period, infants with respiratory distress placed prone rather than supine have higher oxygen saturation $\left(\mathrm{SaO}_{2}\right)$ levels ${ }^{1}$ and better respiratory mechanics. ${ }^{2}$ Improved oxygenation and lung compliance has also been noted in premature infants recovering from respiratory disease. $^{3}$ In term infants with lower respiratory tract infections aged between 2 and 11 months, however, only a modest $(1.7 \%)$ improvement in oxygenation was noted with prone posture. ${ }^{4}$ The effect of posture and the mechanism of any posture related benefits have been less well investigated in convalescent preterm infants. The limited data available suggest that prone posture may still in such infants be associated with improved oxygenation. ${ }^{56}$ In addition, healthy preterm infants have a better response to a carbon dioxide challenge $^{7}$ and reduced frequency of central and mixed apnoeas, bradycardias, and desaturations ${ }^{8}$ when nursed prone. The diaphragm is the primary respiratory muscle in the neonate and performs most of the work of breathing. ${ }^{9}$ Changes in posture by alterations in respiratory system mechanics or lung volume could affect diaphragm function by influencing the resting length of the diaphragm or the degree to which it shortened during inspiration. ${ }^{10}$ We therefore hypothesised that any posture related changes in oxygenation in convalescent infants could be explained by alterations in respiratory muscle strength. The aims of two consecutive studies were to test that hypothesis.

\section{METHODS \\ Protocols}

Infants were eligible for entry into the studies if they had no continuing respiratory problems and were nursed in air. In the first study (study A), infants were examined in three postures: supine, supine with a tilt of $45^{\circ}$, and prone. The supine head up tilt posture was achieved by putting the infant on a firm cot mattress maintained at $45^{\circ}$ tilt. When supine, the infant's head was kept in the midline, but when prone it was turned to the right. The second study (study B) was performed to examine whether the position of the infant's head in the supine posture affected the results of the comparison of the supine and prone postures. Infants were examined as follows: supine with head in the midline, supine with head to the right, and prone with head to the right. The order in which the postures/ head positions were studied was randomised between babies.

Respiratory muscle strength and oxygen saturation were measured in each posture/head position. Infants were studied when awake and about one hour after a feed. All the infants were on full enteral feeds. To assess respiratory muscle strength, the maximum inspiratory pressure (PIMAX) generated during an end expiratory occlusion was measured (fig 1). A face mask was placed over the infant's nose and mouth, with a pneumotachograph (GM Engineering, Kilwinning, Ayrshire, UK) fitted snugly into the distal end of the facemask. Airway pressure changes were measured from a side port on the pneumotachograph using a differential pressure transducer (Validyne MP 45, range $\pm 100 \mathrm{~cm} \mathrm{H}_{2} \mathrm{O}$; Validyne Corporation, Northridge, California, USA). The pressure transducer was calibrated before each recording using a Universal Pressure Meter (Co-Mark, Welwyn Garden City, Herts, UK). The signal from the pressure transducer was amplified using a Gould CD 280 carrier amplifier (Gould, Ilford, Essex, UK). The results were displayed in real time on a Toshiba laptop running Labview software version 4.0 (National Instruments, Austin, Texas, USA) with a $100 \mathrm{~Hz}$ analogue to digital sampling (DAQ 16XE-50; National Instruments). A two way valve was inserted in the distal end of the pneumotachograph. Occlusion of the valve at end expiration allowed expiration but not inspiration. At least three occlusions were performed at end expiration. The exact timing of the manual occlusion was determined by observation of the infant's respiratory movements. Occlusions were maintained until the infant had made at least five respiratory efforts. From the series of occlusions, PIMAX was identified as the largest negative pressure generated. During the measurements the infants were observed for episodes of chest wall distortion. During and immediately after the occlusion, on no occasion did $\mathrm{SaO}_{2}$ fall below $85 \%$. $\mathrm{SaO}_{2}$ was monitored using an Ohmeda Biox 3470-pulse oximeter with an Ohmeda flex II reusable probe. Infants remained in each posture/position for 30 minutes, and then the saturation level was recorded for a five minute period just 


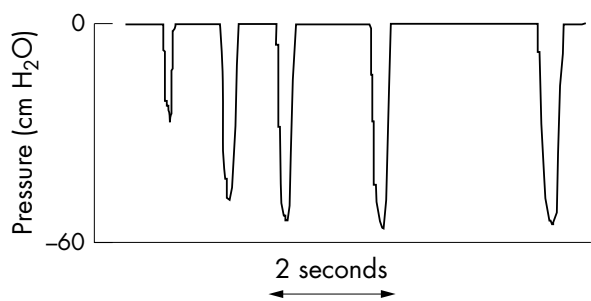

Figure 1 Representative trace of airway pressure during measurement of maximum inspiratory pressure (PIMAX). Airway occlusions were performed at end expiration on at least three separate occasions. Each occlusion was maintained until the infant had made at least five inspiratory efforts. From the series of occlusions, PIMAX was identified as the largest negative pressure generated.

Table 1 Effect of posture on oxygenation and respiratory muscle strength (study A)

\begin{tabular}{|c|c|c|c|}
\hline & Supine & $\begin{array}{l}\text { Supine with } 45^{\circ} \\
\text { head up tilt }\end{array}$ & Prone \\
\hline PIMAX $\left(\mathrm{cm} \mathrm{H} \mathrm{H}_{2} \mathrm{O}\right)$ & $\begin{array}{l}79.1 \\
(46.2-118.2)\end{array}$ & $\begin{array}{l}76.5 \\
(46.4-113.1)\end{array}$ & $\begin{array}{l}67.8 \\
(39.7-90.0)\end{array}$ \\
\hline $\mathrm{SaO}_{2}(\%)$ & 96 (94-99) & $98(96-100)$ & $98(95-100)$ \\
\hline
\end{tabular}

Data are represented as median (range) of the mean values from each of the infants.

PIMAX: supine $v$ prone $\mathrm{p}<0.001 ; 45^{\circ}$ tilt $v$ prone $\mathrm{p}<0.001$

$\mathrm{SaO}_{2}$ : prone $v$ supine $\mathrm{p}<0.001 ; 45^{\circ}$ tilt $v$ supine $\mathrm{p}<0.001$.

PIMAX, Maximum inspiratory pressure; $\mathrm{SaO}_{2}$, oxygen saturation.

before the measurement of Pimax. A spot reading was written down once a minute, and the mean $\mathrm{SaO}_{2}$ for the five minute period was reported. From the infant's medical records, gestational age, birth weight, postnatal age, and weight at the time of measurement were obtained.

\section{Statistical analysis}

Data were tested for normality using the Sharpiro-Wilk W test and found to be distributed normally. Differences in PImax and $\mathrm{SaO}_{2}$ between positions/head posture were assessed for statistical significance using analysis of variance for repeated measures and the Scheffe test for multiple comparisons.

\section{Patients}

In study A, 20 infants ( 12 boys), 12 born less than or equal to 37 weeks of gestational age, were studied. They had a median gestational age of 34.5 weeks (range 25-43) and birth weight of $2.228 \mathrm{~kg}$ (range 0.684-3.740). At the time of study the infants had a median postnatal age of 12.5 days (range 4-91), postconceptional age of 38.5 weeks (range 31-44), and weight of $2.456 \mathrm{~kg}$ (range 1.686-4.286).

In study B, 10 infants (seven boys) were examined. They had a median gestational age of 33 weeks (range 30-36) and birth weight of $1.940 \mathrm{~kg}$ (range 1.152-2.130). At the time of study their median postnatal age was 19.5 days (range 15-63), postconceptional age was 36 weeks (range 35-39), and weight $2.175 \mathrm{~kg}$ (range 1.800-2.360).

The studies were approved by King's College Hospital National Health Service Trust research ethics committee and parents gave informed written consent for their infants to be examined.

\section{RESULTS}

\section{Study A}

Compared with the prone posture, Pimax was higher in the supine posture and supine with $45^{\circ}$ tilt posture $(\mathrm{p}<0.001)$ (table 1). There were no significant differences between the supine and supine with $45^{\circ}$ tilt postures. Compared with in the supine posture, $\mathrm{SaO}_{2}$ was significantly higher in the prone and
Table 2 Individual $\mathrm{SaO}_{2}$ data related to posture (study A)

\begin{tabular}{llll}
\hline \multirow{2}{*}{$\begin{array}{l}\text { Gestational age } \\
\text { (weeks) }\end{array}$} & \multicolumn{2}{l}{$\mathrm{SaO}_{2}(\%)$} & \\
\cline { 2 - 4 } & Supine & Supine/tilt & Prone \\
\hline 43 & 95 & 98 & 97 \\
38 & 97 & 98 & 98 \\
40 & 96 & 97 & 95 \\
38 & 96 & 97 & 99 \\
40 & 97 & 99 & 99 \\
41 & 95 & 96 & 99 \\
40 & 97 & 97 & 97 \\
39 & 94 & 96 & 97 \\
37 & 97 & 98 & 98 \\
33 & 96 & 98 & 98 \\
34 & 99 & 100 & 99 \\
34 & 98 & 98 & 99 \\
34 & 99 & 97 & 98 \\
29 & 96 & 96 & 96 \\
25 & 97 & 98 & 98 \\
34 & 96 & 97 & 98 \\
35 & 96 & 99 & 99 \\
27 & 94 & 99 & 100 \\
27 & 95 & 98 & 100 \\
34 & 97 & 98 & 98 \\
\hline
\end{tabular}

$\mathrm{SaO}_{2}$, Oxygen saturation

Table 3 Effect of head position (study B)

\begin{tabular}{llll}
\hline & $\begin{array}{l}\text { Supine head } \\
\text { midline }\end{array}$ & $\begin{array}{l}\text { Supine } \\
\text { head-right }\end{array}$ & Prone \\
\hline PIMAX $\left(\mathrm{cm} \mathrm{H}_{2} \mathrm{O}\right)$ & 79.4 & 75.4 & 64.4 \\
& $(58.9-89.7)$ & $(57.4-92.8)$ & $(56.6-76.8)$ \\
$\mathrm{SaO}_{2}(\%)$ & $97(93-100)$ & $96.5(93-100)$ & $98.5(95-100)$
\end{tabular}

Data are represented as median (range) of the mean values from each of the infants.

PIMAX: prone $v$ supine (head midline) $p<0.001$; prone $v$ supine (head to right) $p<0.01$.

$\mathrm{SaO}_{2}$ : prone $v$ supine (head midline) $p<0.001$; prone $v$ supine (head to right) $p<0.05$

PIMAX, Maximum inspiratory pressure; $\mathrm{SaO}_{2}$, oxygen saturation.

supine with $45^{\circ}$ tilt postures $(\mathrm{p}<0.001)$ (tables 1 and 2$)$. There were no significant differences between the prone and supine with $45^{\circ}$ tilt postures (table 1 ). Analysis of the results of the 12 infants born at or less than 37 weeks of gestational age also showed the median Pimax to be higher in the supine than the prone posture (74.4 (range 46.2-118.2) $v$ 66.5 (range 39.7-89.5) $\mathrm{cm} \mathrm{H}_{2} \mathrm{O}, \mathrm{p}<0.01$ ), and the median $\mathrm{SaO}_{2}$ to be higher in the prone than the supine posture (median 98\% (range 96-100\%) v 96.5\% (range 94-99\%), $\mathrm{p}<0.001$ ).

\section{Study B}

Compared with in the prone posture, PIMAX was higher in the supine posture both with the head in the midline $(\mathrm{p}<0.001)$ (table 3 ) and with the head to the right $(\mathrm{p}<0.01)$, and $\mathrm{SaO}_{2}$ was lower in the supine posture both with the head in the midline $(\mathrm{p}<0.001)$ and with the head to the right $(\mathrm{p}<0.05)$ (table 3 ). In the supine position, there was no significant difference in Pimax measured with the infant's head in the midline or to the right.

\section{DISCUSSION}

We have shown that respiratory muscle strength, as assessed by measurement of PIMAX, is higher in the supine than the prone posture, whereas the reverse was found with regard to oxygenation. Many factors affect muscle strength. After only a few days of mechanical ventilation, disuse atrophy has been noted in healthy adult baboons. ${ }^{11}$ In addition, respiratory muscle strength is related to maturity at birth, PIMAx being 
higher in term than preterm infants. ${ }^{12}$ To avoid such biases, in each of the two studies the infants acted as their own controls. To assess respiratory muscle strength, the inspiratory pressure generated against an occlusion was measured. PIMAX was measured in the infants during spontaneous crying, and thus we feel was a reflection of respiratory muscle strength rather than respiratory drive. Two occlusion methods can be used: one involves total airway occlusion and the second a unidirectional expiratory valve that permits exhalation but prevents subsequent inspiration. ${ }^{13}{ }^{14}$ Marini et $a l^{13}$ showed that, although the timing of the maximum pressure generated was not affected by the choice of methods, the maximum pressure achieved was almost invariably higher when a unidirectional expiratory valve was used. PImax varies with the lung volume at the time of airway occlusion. ${ }^{15}{ }^{16}$ The likely explanation for the findings of Marini et $a l^{13}$ is that use of a unidirectional expiratory valve resulted in lower lung volumes with improved operating characteristics of the inspiratory muscles. ${ }^{17}$ At low lung volumes, the length of the inspiratory muscles and the geometry of the diaphragm are optimised. ${ }^{13} 17$ Also, outward recoil of the relaxing chest wall near residual volume assists the inspiratory musculature in achieving inspiratory force ${ }^{18}$ In this study, we used an occlusion method, which allowed exhalation but not inspiration, and showed significant differences in Pimax between the prone and supine postures.

In the first study, PIMAx was higher in the supine and supine with $45^{\circ}$ head up tilt postures than in the prone posture. In the supine posture, the infant's head position was in the midline, whereas, in the prone posture, it was held to the right. Thus we could not exclude the possibility that our results were due to differences in head position, PImax measurements perhaps being more difficult to make when the infant's head was turned to the right. In addition, head turning results in deformation of the airways. ${ }^{19}$ A second study was therefore performed in which each infant was assessed in both the supine and prone posture with the head to the right, as well as in the supine posture with the head to the midline. The supine posture, regardless of head position, was associated with a significantly higher PIMAX than the prone posture. There was no significant difference in the median Pimax between the two head positions in the supine posture. Pimax was determined as the maximum pressure achieved during an occlusion maintained for five breaths, and the same technique was applied in all postures and head positions. Thus our results indicate that PIMAX is influenced by posture.

Changing from the supine to the prone posture in healthy full term infants has been reported to be associated with lessened thoracoabdominal incoordinaton and increased tidal volume. $^{20}$ In our population we did not observe chest distortion but, as we did not use respiratory inductive plethysmography, we cannot be confident that this did not occur in the prone position. It has been suggested that the advantageous effects of the prone posture in healthy full term neonates could be due to changes in diaphragm function. ${ }^{20}$ The authors felt that the prone position, by permitting the area of greater excursion of the diaphragm to be unopposed by hydrostatic pressure, would increase diaphragmatic work and allow more efficient ventilation. ${ }^{21}$ In addition, they emphasised that the prone posture increases intra-abdominal pressure, passively distending the diaphragm and stabilising the compliant chest wall. ${ }^{22}$ The postulated effect of the prone posture on diaphragmatic function in healthy term neonates ${ }^{20}$ is not supported by either our findings of a higher PIMAX in the supine compared with the prone posture or postural differences in diaphragm configuration recently described in healthy term neonates. ${ }^{10}$ Using ultrasonographic examination, Relian et al ${ }^{10}$ showed that the diaphragm was significantly thicker at end expiratory volume in the prone than in the supine posture. In addition, the prone posture was associated with greater diaphragm thickening during inspiration. It was concluded that, in the prone posture, the diaphragm and diaphragm shortening during tidal breathing is greater. There were similar findings in a canine model ${ }^{23}$ The degree of diaphragm shortening in the prone compared with the supine posture ${ }^{10}$ was similar to that resulting from a lung volume increase of $15-20 \%$ of vital capacity. ${ }^{24}$ In adults such an increase in lung volume results in a $40-50 \%$ reduction in diaphragm strength and endurance. ${ }^{25}$ Thus it is not surprising that we found that PImax was lower in the prone than in the supine posture.

Prone compared with supine posture has been associated with improved oxygenation outside the perinatal period in preterm infants with chronic oxygen dependency. ${ }^{56}$ The infants we examined were convalescent, without continuing respiratory problems, and their average postconceptional age was term. Posture related changes in thoracoabdominal synchrony have been reported in both preterm ${ }^{2}$ and term ${ }^{20}$ infants. In the term infants, the reduced thoracoabdominal asynchrony in the prone posture was associated with improved ventilation and increased respiratory drive. ${ }^{20}$ Such changes may therefore explain the improved oxygenation observed by us in the prone posture.

A possible explanation for the higher oxygenation in the prone posture may be a higher lung volume, resulting from reduced cephalad stress on the diaphragm. Others, however, have suggested that lung volume may be lower in the prone position because of the compressing effect of the infant's body weight on the relatively compliant chest wall. ${ }^{26}$ The impact of posture on functional residual capacity of preterm infants at a postconceptional age of near term is unexamined but, in healthy full term infants, no posture related significant changes in either functional residual capacity or effective pulmonary blood flow were shown in the first days after birth. ${ }^{26}$

Prone posture also influences the likelihood of gastrooesophageal reflux. Nursing infants prone is associated with less severe gastro-oesophageal reflux in both symptomatic ${ }^{27}$ and asymptomatic ${ }^{28}$ infants and with less gastric residual. In addition, prone positioning resulted in a decreased number of apnoeic episodes in preterm infants with gastro-oesophageal reflux and theophylline resistant apnoea. ${ }^{29}$

Oxygenation was significantly higher in the supine with $45^{\circ}$ head up tilt posture than in the supine posture. A head tilt of $15^{\circ}$ has been associated with a reduction in the frequency of hypoxaemic episodes in prematurely born infants. ${ }^{30}$ In addition, head elevation by $20-45^{\circ}$ has been shown to improve oxygenation. ${ }^{31}{ }^{32}$ Possible mechanisms include improved ventilation/perfusion matching. ${ }^{30}$ It has been suggested that tilting may also improve diaphragm activity. ${ }^{31}$ Our results, however, do not support this hypothesis, ${ }^{31}$ because, although Pimax was higher in the supine with $45^{\circ}$ head up tilt posture than in the prone posture, there was no significant difference in the Pimax results obtained in the supine with $45^{\circ}$ head up tilt posture compared with the supine posture.

We conclude that oxygenation is significantly better in convalescent preterm and term infants when they are nursed prone rather than supine. Differences in respiratory muscle strength seem unlikely to explain these posture related changes in oxygenation.

\section{ACKNOWLEDGEMENTS}

G D was supported by a Children Nationwide Medical Research Fund/ Nestle Research Fellowship. We thank Ms Sue Williams for secretarial assistance.

A G and G F R were responsible for the study design. G D and A H were research fellows involved in data collection. L P and M McG, BSc students, assisted the research fellows in data collection. All authors were involved in data analysis and producing the manuscript.

\section{Authors' affiliations}

G Dimitriou, A Greenough, L Pink, A McGhee, A Hickey, G F

Rafferty, Children Nationwide Regional Neonatal Intensive Care Unit, King's College Hospital, London, UK 


\section{REFERENCES}

1 Martin RJ, Hernell N, Rubin D, et al. Effect of supine and prone positions on arterial oxygen tension in the preterm infant. Pediatrics 1979;63:528-31.

2 Wolfson MR, Greenspan JS, Deoras KS, et al. Effect of position on the mechanical interaction between the rib cage and abdomen in preterm infants. J Appl Physiol 1992;72:1032-8.

3 Wagaman MJ, Shutack JG, Mommiian AS, et al. Improved oxygenation and lung compliance with prone positioning of neonates. J Pediatr 1979:94:787-91.

4 Levene S, McKenzie SA. Transcutaneous oxygen saturation in sleeping infants: prone and supine. Arch Dis Child 1990;65:524-6.

5 McEvoy C, Mendoza ME, Bowling S, et al. Prone positioning decreases episodes of hypoxemia in extremely low birth weight infants (1000 grams or less) with chronic lung disease. J Pediatr 1997; 130:305-9.

6 Baird TM, Paton JB, Fisher DE. Improved oxygenation with prone positioning in neonates: stability of increased transcutaneous $\mathrm{PO}_{2}$. J Perinatol 1991:11:315-18.

7 Martin RJ, DiFiore JM, Korenke CB, et al. Vulnerability of respiratory control in healthy preterm infants placed supine. J Pediatr 1995; 127:609-14

8 Kurlak LO, Ruggins NR, Stephenson TJ. Effect of nursing position on incidence, type and duration of clinically significant apnoea in preterm infants. Arch Dis Child Fetal Neonatal Ed 1994;71:F16-19.

9 Murphy T, Woodrum D. Functional development of respiratory muscles. In: Polin RA, Fox WW, eds. Fetal and neonatal physiology. Philadelphia: WB Saunders Company, 1998:1071-84.

10 Relian VK, Nakashima JM, Gutman A, et al. Effects of supine and prone position on diaphragm thickness in healthy term infants. Arch Dis Child 2000;83:234-8.

11 Anzueto A, Peters J, Tobin M, et al. Effects of prolonged controlled mechanical ventilation on diaphragmatic function in healthy adult baboons. Crit Care Med 1997:25:1187-90.

12 Dimitriou G, Greenough A, Dyke H, et al. Maximal airway pressures during crying in healthy preterm and term infants. Early Hum Dev 2000;57: 149-56.

13 Marini JJ, Smith TC, Lamb V. Estimation of inspiratory muscle strength in mechanically ventilated patients: the measurement of maximal inspiratory pressure. J Crit Care 1986;1:32-8

14 Caruso P, Friedrich C, Denari S, et al. The unidirectional valve is the best method to determine maximal inspiratory pressure during weaning. Chest 1999;115:1096-101.

15 Black LF, Hyatt RE. Maximal static respiratory pressures in generalized neuromuscular disease. Am Rev Respir Dis 1971;103:641-50.

16 Byrd RB, Hyatt RE. Maximal static respiratory pressures in chronic obstructive lung disease. Am Rev Respir Dis 1968;98:848-56.
17 Polkey MIC, Hamnegard CH, Hughes PD, et al. Influence of acute lung volume change on contractile properties of human diaphragm. J Appl Physiol 1998;85: 1322-8

18 Agostoni E, Mead J. Statics of the respiratory system. In: Fenn WO Rahn $\mathrm{H}$, eds. Handbook of physiology. Washington DC, American Physiological Society, 1964:397-409.

19 Shen X-M, Zhao W, Huang D-S, et al. Effect of positioning on pulmonary function of newborns: comparison of supine and prone position. Pediatr Pulmonol 1996;21:167-70.

20 Adams JA, Zabalera I, Sackner MA. Comparison of supine and prone non-invasive measurements of breathing patterns in full term newborns. Pediatr Pulmonol 1994;18:8-12.

21 Mendoza JC, Roberts RL, Cook LN. Postural effects on pulmonary function and heart rate of preterm infants with lung disease. J Pediatr $1991 ; 118: 445-8$

22 Lioy J, Manginello FP. Clinical and laboratory observations: a comparison of prone and supine positioning in the immediate postextubation period. J Pediatr 1988;112:982-4

23 Margulies SS, Farkas GA, Rodarte JR. Effects of body position and lung volume in situ operating length of canine diaphragm. J Appl Physiol 1990;69:1702-8.

24 Cohn DB, Benditt JO, Eveloff SE, et al. Diaphragm thickening during inspiration. J Appl Physiol 1997;83:291-6.

25 McCool FD, Tzelepis GE, Leith DE, et al. Oxygen cost of breathing during fatiguing inspiratory resistive loads. J Appl Physiol 1989;66:2045-55

26 Aiton NR, Fox GF, Alexander J, et al. The influence of sleeping position on functional residual capacity and effective pulmonary blood flow in healthy neonates. Pediatr Pulmonol 1996;22:342-7.

27 van den Plas Y, Sacre-Smits L. Seventeen hour continuous oesophageal $\mathrm{pH}$ monitoring in the newborn: evaluation of the influence of position in babies. J Pediatr Gastroenterol Nutr 1985;4:356-61.

28 Tam $\mathbf{P}$, Lin LH. Fifteen hour continuous oesophageal pH monitoring: influence of position on gastro-oesophageal reflux among symptomatic babies. Chung-Hua Min Kuo Hsiao Erh Ko i Hsueh Hui Tsa Chih 1993;34:14-21.

29 Newell S, Booth I, Durbin G, et al. Gastro-oesophageal reflux in preterm infants. Arch Dis Child 1989:64:780-6.

30 Jenni OG, von Siebenthal K, Wolf $M$, et al. Effect of nursing in the head elevated tilt position $\left(15^{\circ}\right)$ on the incidence of bradycardic and hypoxemic episodes in preterm infants. Pediatrics 1997;100:622-5.

31 Dellagrammaticas HD, Kapetanakis J, Papadimitriou $M$, et al. Effect of body tilting on physiological functions in stable very low birthweight neonates. Arch Dis Child 1991;66:429-32.

32 Thoresen M, Cowan F, Whitelaw A. Effect of tilting oxygenation in newborn infants. Arch Dis Child 1988:63:315-17. 